\title{
Jagged1 is Clinically Prognostic and Promotes Invasion of Glioma-Initiating Cells by Activating NF-kB(p65) Signaling
}

\author{
Long Haia,b,ce $\quad$ Peidong Liu ${ }^{b}$ Shengping $\mathrm{Yu}^{\mathrm{b}} \quad \mathrm{Li} \mathrm{Yi}^{\mathrm{b}} \quad$ Zhennan Tao ${ }^{\mathrm{b}} \quad$ Chen Zhang ${ }^{\mathrm{f} g}$ \\ Iruni Roshanie Abeysekera ${ }^{d}$ Tao Li $^{b}$ Luqing Tong ${ }^{b}$ Haiwen Ma ${ }^{b}$ Bo Liu ${ }^{b}$ \\ Yang Xie $^{\mathrm{b}} \quad$ Xingchen Zhou $^{\mathrm{b}} \quad \mathrm{Yu}_{\mathrm{Lin}}{ }^{\mathrm{b}} \quad$ Meng Zhu $^{f} \quad$ Kai Zhang $^{\mathrm{b}} \quad$ Bingcheng Ren $^{\mathrm{b}}$ \\ Haolang Ming ${ }^{b}$ Yubao Huang ${ }^{b}$ Xuejun Yang ${ }^{\text {b,c,e }}$
}

aDepartment of Radiation Oncology, Henan Cancer Hospital, The Affiliated Cancer Hospital of Zhengzhou University, Zhengzhou, 'Department of Neurosurgery, Tianjin Medical University General Hospital, Laboratory of Neuro-Oncology, Tianjin Neurological Institute, Tianjin, CKey Laboratory of Post-trauma Neuro-Repair and Regeneration in Central Nervous System, Ministry of Education, Tianjin, dDepartment of Physiology and Pathophysiology, Tianjin Medical University, Tianjin, ${ }^{e}$ Chinese Glioma Cooperative Group (CGCG), 'Department of Neurosurgery, The Affliated Hospital of Qingdao University, Qingdao, China, 9Department of Neuro-Oncology, The University of Texas MD Anderson Cancer Center, Houston, USA

\section{Key Words}

Jagged 1 • Glioma-initiating cells (GICs) • NF-kB(p65) • Invasion

\begin{abstract}
Background/Aims: Jagged1 is the ligands of the Notch signaling and has been shown to promote glioma-initiating cells (GICs) in glioblastoma. The role of Jagged1 in GICs invasion and underlying molecular mechanisms remain unclear. Methods: Survival data from R2 genomics analysis, the Cancer Genome Atlas (TCGA), the Chinese Glioma Genome Atlas (CGGA) and visualization platform database were used to evaluate the effects of Jagged 1 on overall patient survival. we investigated Jagged1 induced the GICs cells' invasion by matrix degradation assays and Transwell cell invasion assays in vitro, then we further explored the underlying molecular mechanisms using Co-immunoprecipitation (co-IP) analysis. Results: High expression of Jagged1 in human glioma was associated with poor survival. Clinical data analysis showed that the Jagged1 was positively correlated with NF- $\mathrm{kB}(\mathrm{p} 65)$. Jagged1induced invasion of GICs cells through activation of NF-kB(p65) pathway. In vivo, knockdown of Jagged 1 could suppress the tumorigenicity of GICs cells through NF-kB(p65) signaling. Conclusion: Insights gained from these findings suggest that Jagged1 plays an important oncogenic role in GICs malignancy by activation of NF-KB(p65) signaling, and Jagged1 could be employed as an effective therapeutic target for GICs.

L. Hai, P. Liu, S. Yu, L. Yi and Z. Tao contributed equally to this work.




\section{Cellular Physiology Cell Physiol Biochem 2018;51:2925-2937 and Biochemistry Published online: 14 December $2018 \begin{aligned} & \text { DOI: } 2018 \text { The Author(s). Published by S. Karger AG, Basel } \\ & \text { www.karger.com/cpb }\end{aligned}$}

Hai et al.: Jagged1 regulated GICs Invasion Through NF-kB(p65)

\section{Introduction}

Glioblastoma multiforme (GBM) is the most frequent and aggressive of brain malignancies [1]. Current standard therapy after initial diagnosis includes maximal safe surgical resection and a combination of radiation therapy and concurrent adjuvant temozolomide (TMZ) chemotherapy [2]. Although surgical resection aims to remove a significant portion of the visible tumor mass, it is unable to eradicate invasive and migratory cells [3]. Moreover, GBM cells respond unpredictably to radio-chemotherapy, resulting in continual observation and further relapses. Recurrent cases of GBM are common and relapsed patients unfortunately have a dismal survival of less than 15 months [4].

Recently, a subpopulation (glioma-initiating cells, GICs) with augmented tumorinitiating potential and stem cell behavior has been identified in glioblastomas [5]. It is assumed that recurrence results from GICs, GICs are inherently chemo- and radio-resistant, and are highly invasive, suggesting that therapeutic approaches targeting GICs would have enhanced antitumor efficacy [6-8].

Notch signaling, an evolutionarily conserved pathway that mediates direct cell-cell interactions, play a crucial part in maintenance and self-renewal of GICs $[9,10]$. In mammals, there are five ligands (Jagged1, Jagged2, Delta-like [Dll]1, Dll3, and Dll4) and four Notch receptors (Notch1-4). Notch signaling is activated by ligand-receptor interactions between neighboring cells, releasing the Notch intracellular domain (NICD) into the nucleus, whereby the NICD binds to the transcription factor CSL. The NICD/CSL complex causes the expression of target genes, such as those of the Hairy enhancer of spit (Hes) family [11].

Notch ligands are present or upregulated in several human malignancies [12]. Jagged1 has also been proven to play several vital roles in multiple aspects of cancer biology, including tumor angiogenesis, $[13,14]$ neoplastic cell growth, $[15]$ cancer stem cells (CSCs), $[16,17]$ epithelial-mesenchymal transition (EMT) in several types of cancer [18, 19]. Jagged1 is frequently overexpressed on both glioma cells and tumor-associated endothelial cells [16, 20]. Moreover, studies have shown that down-regulation of Jagged 1 induces apoptosis and inhibits proliferation in glioma cell lines [21]. These data suggest that Jagged1 may play a central role in glioma cells. Asmost studies have focused on the effects of inhibiting the Notch receptor and its downstream signaling, specific inhibition of the ligand Jagged 1 in GICs invasion has not been fully explored.

In this study, we found that Jagged1 knockdown in GICs suppressed invasion using in vitro and in vivo models. Jagged1-mediated Notch1 signaling activation was able to increase invasion in glioma mainly though upregulation of NF- $\mathrm{BB}(\mathrm{p} 65)$, Our findings indicate that Jagged1 is a promising therapeutic target for preventing GICs invasion progression.

\section{Materials and Methods}

Datasets used in this study

Gene expression profiling datasets were obtained from the Chinese Glioma Genome Atlas (CGGA, http:// www.cgga.org.cn), including the mRNA array of 128 samples and the mRNA sequencing of 144 samples. In addition, 540 samples of GBM from the Cancer Genome Atlas (TCGA, https://tcga-data.nci.nih.gov/tcga/). R2:Genomics Analysis and Visualization Platform (http://r2.amc.nl) was used to acquire Jagged1 mRNA expression in glioma and normal brain tissues. Microarray data of GEO (http://www.ncbi.nlm.nih.gov/geo), GDS3885 was enrolled in this study. GDS3885 profile included microarray data from 27 panels of GSCs and 36 panels of NSTCs. Cluster analyses were performed and visualized using Cluster/Java Treeview. ChIPBase v2.0 (http://rna.sysu.edu.cn/chipbase/) was used to perform Pearson's correlation tests. The Retrieval of Interacting Genes/Proteins (STRING database v10.5) resource was utilized for PPI network analysis and prediction of protein-protein interactions. 


\section{Cellular Physiology Cell Physiol Biochem 2018;51:2925-2937 \begin{tabular}{l|l|l} 
and Biochemistry Published online: 14 December 2018 & $\begin{array}{l}\text { (c) } 2018 \text { The Author(s). Published by S. Karger AG, Basel } \\
\text { www.karger.com/cpb }\end{array}$ \\
\hline
\end{tabular}}

Hai et al.: Jagged1 regulated GICs Invasion Through NF-kB(p65)

\section{Sample collection}

GBM tissues were collected from the Department of Neurosurgery, Tianjin Medical University General Hospital between July 2008 and December 2012. Collected specimens were split into three parts for 4\% paraformaldehyde(PFA)fixation. All samples were histologically graded according to the 2007 World Health Organization (WHO) Classification of Nervous System Tumors. Patients did not receive radiotherapy and chemotherapy before surgery. Written informed consent was obtained from all donors and their relatives. The study was carried out in accordance with the principles of the Helsinki Declaration and approved by the ethical committed of Tianjin Medical University General Hospital.

\section{Cell culture}

Human GBM cells U87, U251 were obtained from Cell Bank Type Culture Collection of the Chinese Academy of Sciences (Shanghai, China). The cells were cultured in Dulbecco's modified Eagles medium (DMEM, Gibco, Gaithersburg, MD, USA) supplemented with 10\% fetal bovine serum (FBS; Gibco), 100 U/ml penicillin, and $100 \mu \mathrm{g} / \mathrm{ml}$ streptomycin and incubated at $37^{\circ} \mathrm{C}$ in $5 \% \mathrm{CO}$. The generation and identification of U251 and U87 GSCs was performed as we previously described [22]. $\gamma$-secretase inhibitor MK0752 was purchase from Selleck Chemicals. Purified Jagged1 ligand (R\&D Systems Europe, Lille, France) was added to the cell medium for 7 days.

\section{Real time-PCR analyses}

RNA isolation and real-time PCR Total RNA fromcells was extracted using Trizol (Invitrogen, Carlsbad, CA, USA) according to the manufacturer's protocol. Then cDNA was synthesized using $2 \mu \mathrm{g}$ of RNA via reverse transcriptional kit abide by manufacturer' s protocol. Real-time PCR was used to evaluate Jagged1 mRNA levels. The PCR primers were provided by Sheng Gong Company and the primer sets were as follows: forward: 5'-TCGGGTCAGTTCGAGTTGGA-3' and reverse: 5'-CGTTCACGTTCTGCATGGAC-3'.

\section{Western blot arrays}

Western blotting was carried out as previously described [23]. The primary antibodies used in this study were as follows: NICD and NF-kB(p65) antibodies were obtained from Cell Signaling Technology (dilution1:100, CST, USA); pY421-Cortactin, MMP-2, MMP-9 and Hes1 was from Abcam(dilution1:1000, USA). The expression of $\beta$-actin (dilution1:2000, Abcam,USA) was used as normalization antibody and loading control.

\section{Co-immunoprecipitation}

Co-immunoprecipitation assay was performed as described previously [24]. Cells were harvested in IP lysis buffer (Thermo Fisher Scientific, USA). The Cell lysates were pre-cleared with $40 \mu \mathrm{l}$ of protein A/Gagarose beads (Santa Cruz Biotechnology,USA) and immunoprecipitated with either a primary antibody or control IgG (Santa Cruz Biotechnology) at $4{ }^{\circ} \mathrm{C}$ overnight, followed by $2 \mathrm{~h}$ of incubation at $4{ }^{\circ} \mathrm{C}$ with $40 \mu \mathrm{l}$ of protein A/G-agarose beads (Santa Cruz Biotechnology) maintained with constant agitation. The beads were then washed with wash buffer, suspended in sample buffer, and boiled, and the eluted proteins were assessed using Western blot.

\section{Invasion assay}

Transwell invasion assays were performed using transwell filters (Costar, USA) coated with Matrigel $(60-80 \mu \mathrm{l})$ on the upper surface of the polycarbonic membrane (diameter $6.5 \mathrm{~mm}$, pore size $8 \mu \mathrm{m})$. Glioma cells $\left(5 \times 10^{4}\right.$ in $200 \mu \mathrm{l}$ DMEM without FBS $)$ were seeded on the top side of the Matrigel-coated chambers. The lower compartments were filled with DMEM supplemented with $10 \%$ FBS. Following $24 \mathrm{~h}$ incubation, the non-invading cells were removed from the upper surfaces of the invasion membranes and the cells on the lower surface were stained with crystal violet. Five visual fields were randomly selected from each membrane. All experiments were repeated three times independently. 


\section{Cellular Physiology Cell Physiol Biochem 2018;51:2925-2937 \begin{tabular}{l|l|l} 
and Biochemistry Published online: 14 December 2018 & $\begin{array}{l}\text { (c) } 2018 \text { The Author(s). Published by S. Karger AG, Basel } \\
\text { www.karger.com/cpb }\end{array}$ \\
\hline
\end{tabular}}

\section{Immunohistochemistry and Immunofluoresence}

Paraffin-embedded specimens were cut into 5- $\mu \mathrm{m}$ sections. A standard immunostaining procedure was performed using the primary antibody solution [23]. Images were acquired using an Olympus VANOX microscopy at magnifications of $\times 200$. The immunohistochemical staining results were evaluated by two experienced pathologists. Immunofluorescence stain was performed as described previously [22]. Primary antibodies against CD133 (1:100; ab19898), Nestin (1:100; ab105389), Notch1 (1:200; ab44986) were used. Cells were observed and imaged with a fluorescence microscopy (IX73, Olympus, Tokyo, Japan). Alexa fluor-labeled anti-rabbit or anti-mouse antibody (Invitrogen, USA; 1:500) was added to the incubation. The nuclei were stained with DAPI (Sigma, USA).

\section{Knockdown assay}

A nontargeting siRNA scramble control and siRNA targeting either NF-kB(p65) (SignalSilence ${ }^{\circledR}$ NF- $\mathrm{kB}$ p65 siRNA \#6261, Cell Signaling) were transfected into glioma cells using Lipofectamine 3000 (Invitrogen) according to the manufacturer's instructions. The cells were harvested for western blot assays $48 \mathrm{~h}$ posttransfection. For lentivirus transfections, methods used for lentivirus production and infection were performed as described previously [22]. Lentivirus containing the Jagged 1 sequence and a negative control sequence was obtained from Santa Cruz. All of the cell lines were infected with lentivirus for $48 \mathrm{~h}$ prior to performing the assays, according to the manufacturer's instructions.

\section{Matrix Degradation Assay}

For matrix degradation assay, this protocol is adapted from Artym et al [25]. In brief, $12 \mathrm{~mm}$ coverslips were inverted onto FITC-conjugated gelatin (Invitrogen). A total of 20, 000 cells were seeded on each coverslip, incubated for $8 \mathrm{~h}$, and processed for IF. To quantify invadopodia function condition, the area of matrix degraded round the cells was quantified with an identical signal threshold for the FITC-gelatin fluorescence for every image. The measured degraded area was the area where the fluorescence signal below the threshold as measured with Image J. The quantified area was normalized against the total number of cells.All images were taken using an Olympus FV-1000 confocal microscope. Each experiment was repeated at least three times to ensure reliability

\section{Nude mouse intracranial model}

BALB/c-A nude mice at 4 weeks of age were purchased from the Animal Centerat the Cancer Institute at the Chinese Academy of Medical Science (Beijing, PR China). A total of $5 \times 10^{5} \mathrm{GBM}$ cells infected with lenti-NC, lenti-Jagged1 virus were implanted stereotactically using cranial guide screws. Bioluminescence imaging was used to detect intracranial tumor growth on days 7,14 , and 21 . Two mice randomly selected from each group were sacrificed. The brains were carefully extracted and fixed in $10 \%$ formalin, then embedded in paraffin for H\&E and IHC analysis. Overall survival times were closely monitored and recorded. All animal research followed the internationally recognized guidelines and national regulations.

\section{Statistical analyses}

Statistical analyses were performed using GraphPad Prism 6.0(GraphPad, La Jolla, CA, USA) and SPSS version 19.0 (SPSS, Chicago, IL, USA). A circus plot was achieved with the circlize package of R. A one-way ANOVA was performed for comparisons between different groups. All data are presented as mean \pm SD. $\mathrm{P}<0.05$ was considered to be statistically significant.

\section{Results}

High expression of Jagged1 in human glioma was associated with poor survival

To determine whether Jagged1 is clinically correlated with glioma progression, survival data from R2 genomics analysis and visualization platform database were used to evaluate the effects of Jagged1 on overall patient survival. Contrasting to normal tissue or lower grade glioma, Jagged 1 was significantly upregulated in GBM patients according to Glioma France, Glioma Sun, CGGA and TCGA datasets (Fig. 1A-G). Accordingly, The Kaplan-Meier survival analysis revealed that patients with high levels of Jagged1 possessed shorter overall survival 


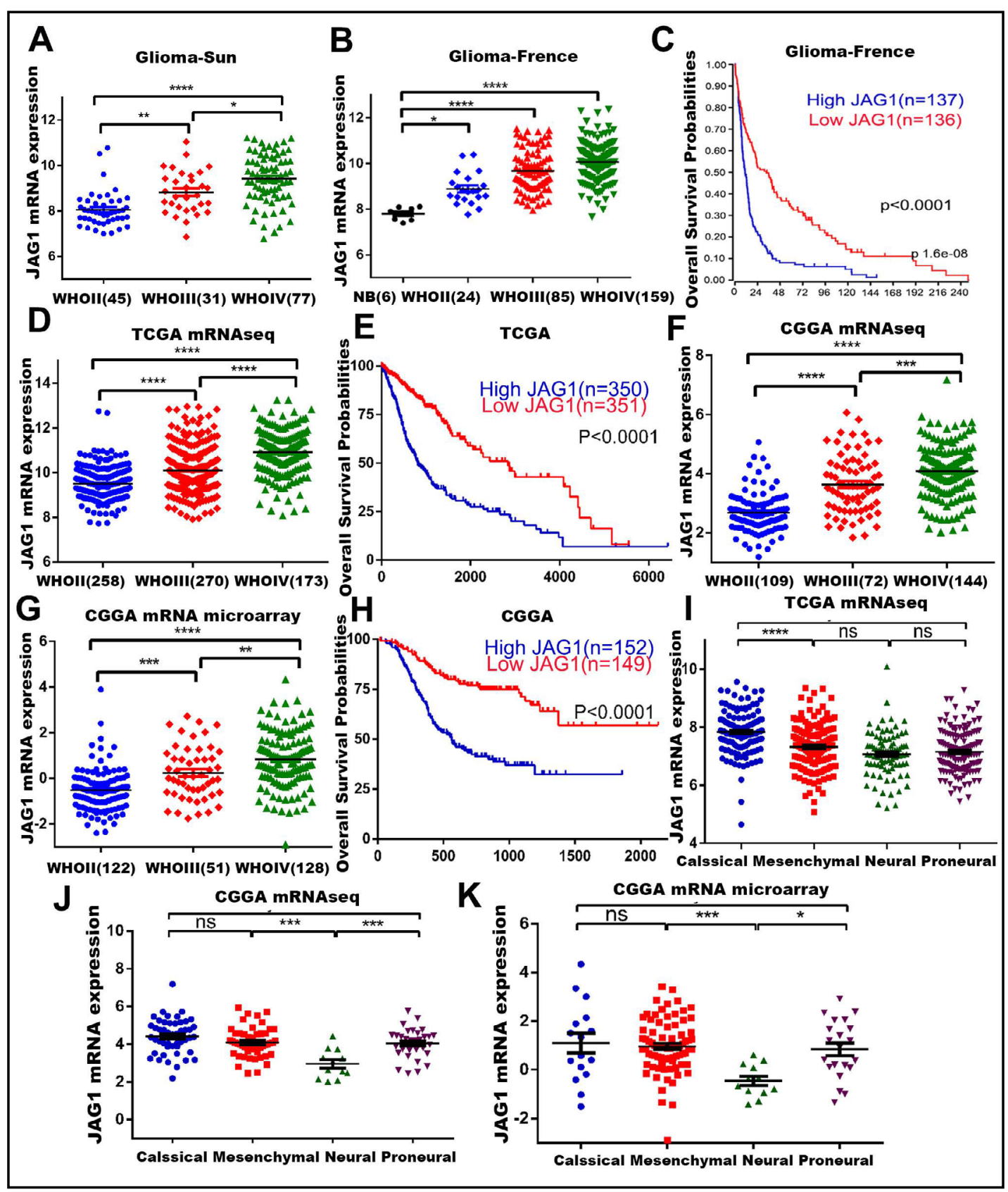

Fig. 1. Jagged1 expression was increased in glioma, this elevated Jagged1 expression was a prognostic indicator of poor overall survival for glioma patients. (A, B, D, F and G) Jagged1 level was increased in WHO II, III, and IV compared with non-tumor brain tissues from the Glioma France, Glioma Sun, CGGA and TCGA datasets. NB: non-tumor brain tissue. (C, E and H) Kaplan-Meier survival curve analysis indicated that patients with Jagged1 overexpression had a significantly shorter overall survival in glioma patients. (I-K) The levels of Jagged1 were analyzed in GBM tissues from TCGA datasets and CGGA datasets. Jagged1 was significantly upregulated in classical and proneural subtypes of GBM.

(OS) time than patients with low levels of Jagged1, $P<0.0001$ (Fig. 1C, E and F). To further confirm the Jagged1 expression results in GBM, we analyzed data in the TCGA and CGGA. The results of the analysis revealed that Jagged 1 was significantly upregulated in classical and proneural subtypes of GBM. (Fig. 1I-K). All these results indicated that Jagged1 might function as an oncogene involved in the development and progression of GBM. 


\section{Cellular Physiology

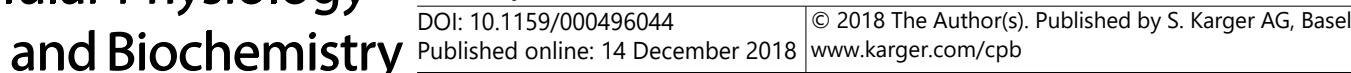

Hai et al.: Jagged1 regulated GICs Invasion Through NF-kB(p65)

Notch1 pathway is preferentially expressed by GICs

We used a GEO microarray data set (GDS3885) and found that the Notch1 pathways significantly upregulated in GICs relative to the matched non-tumour stem cells (NSTCs) (Fig. 2A). Immunohistochemical staining of Notch1, Nestin, Jagged1 and CD133 were expressed in GBM cells adjacent to endothelial cells. (Fig. 2B). Consistently, elevated expression of Notch1 in GICs was validated by immunofluorescence in U87 GICs and U251 GICs (Fig. 2C, D). Coexpression of Notch1 with Nestin or CD133 was detected in GICs tumourspheres. Overall, these data demonstrate that Notch1 pathway is preferentially expressed in GICs.

Clinical data analysis showed that the Jagged 1 was positively correlated with $N F-\kappa B(p 65)$

To investigate whether Jagged 1 expression is correlated with NF- $\mathrm{B}(\mathrm{p} 65)$ expression, we analyzed data in the TCGA and found that Jagged1 was correlated with NF- $\mathrm{BB}(\mathrm{p} 65)$ in total GBM samples (Fig. S1C, D - for all supplemental material see www.karger. com/10.1159/000496044/). The PPIs network was built from the STRING resource also confirmed this finding (Fig. S1B). Pearson's correlation was performed with these factors in TCGA data set. In GBM of TCGA, Jagged1 showed high concordance with MMP2 and MMP9 (Fig. S1C).

\section{Jagged1 regulated GICs cells invasion}

In Transwell cell invasion assays, representative data showed that dramatically increased the invasive ability of GICs cells (Fig. S1E, F), indicating that Jagged1 may have a significant effect on cell invasion. Furthermore, matrix degradation assays also confirmed this result. Jagged1 significantly increased invadopodia formation and matrix degradation. Meanwhile, MK0752 (a Notch1 pathway inhibitor) notably decreased the invasiveness of glioma cells, the matrix area digested by invadopodia (Fig. 3A, B). MK0752 significantly suppressed the Hes1, NF- $\mathrm{BB}(\mathrm{p} 65)$, pY421-Cortactin, MMP-2, and MMP-9 expression (Fig. 3C, D). Whereas, in Jagged1 ligand treatment GICs cells, Jagged1 increased Hes1, NF- $\kappa B$ (p65), pY421-Cortactin, MMP-2 and MMP-9 expression. These data indicated that Jagged1 induced the GICs cells' invasion.

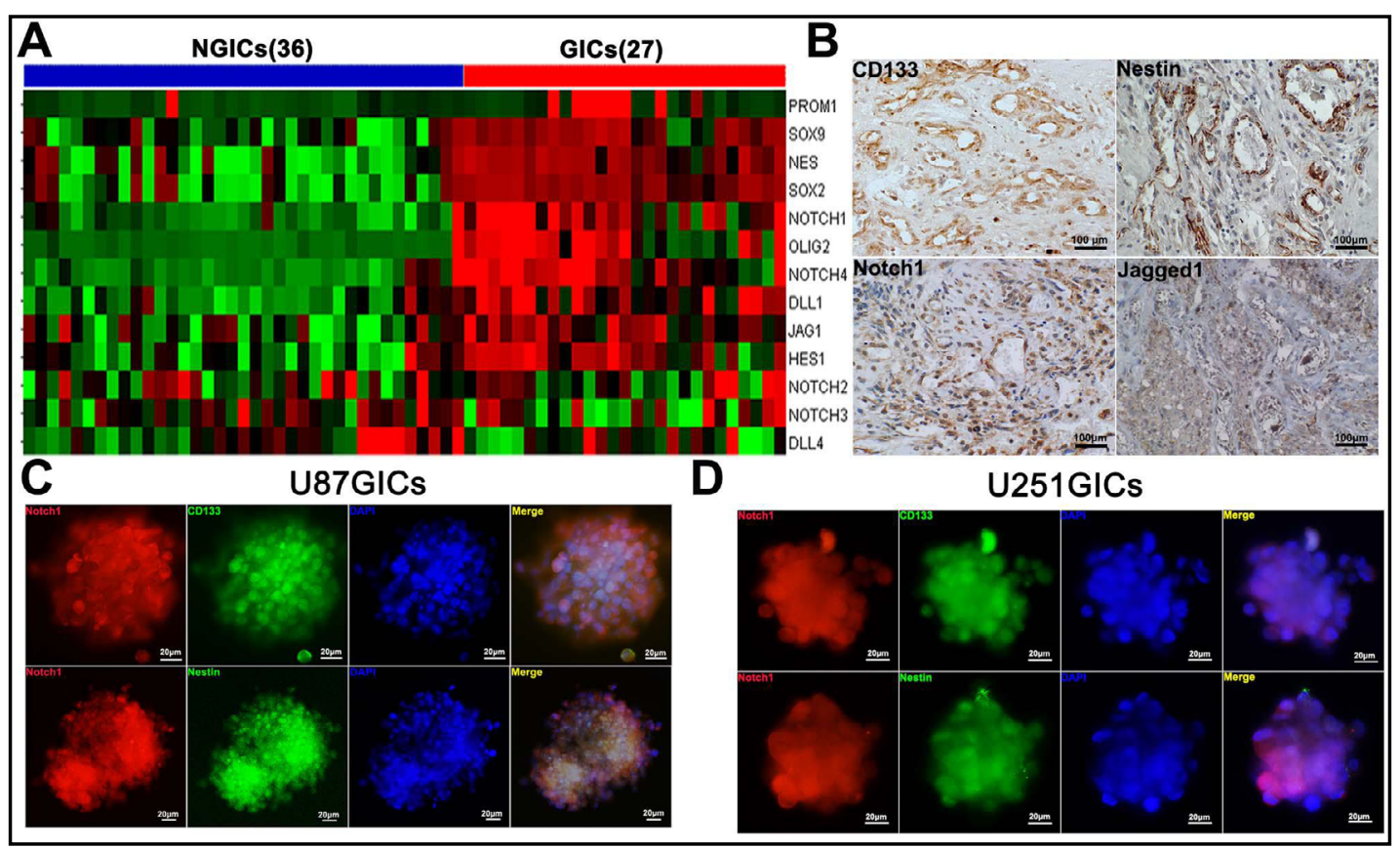

Fig. 2. Notch1 pathway contributes to stemness. (A) Expression heat map of Notch1 pathway in GSC lines $(n=27)$ and NSTC lines $(n=36)$ from GEO profiles (GEO: GDS3885). Jagged1 was significantly upregulated in GSCs relative to the non-tumour stem cells (NSTC). (B) Immunohistochemical staining of Notch1, Nestin, Jagged1 and CD133 were expressed in GBM cells adjacent to endothelial cells. The scale bar corresponds to $100 \mu \mathrm{m}$.(C, D)Co-expression of Notch1 and Nestin, Notch1 and CD133 showing the corresponding colocalization in the U87 GICs and U251 GICs. The scale bar corresponds to $20 \mu \mathrm{m}$. 


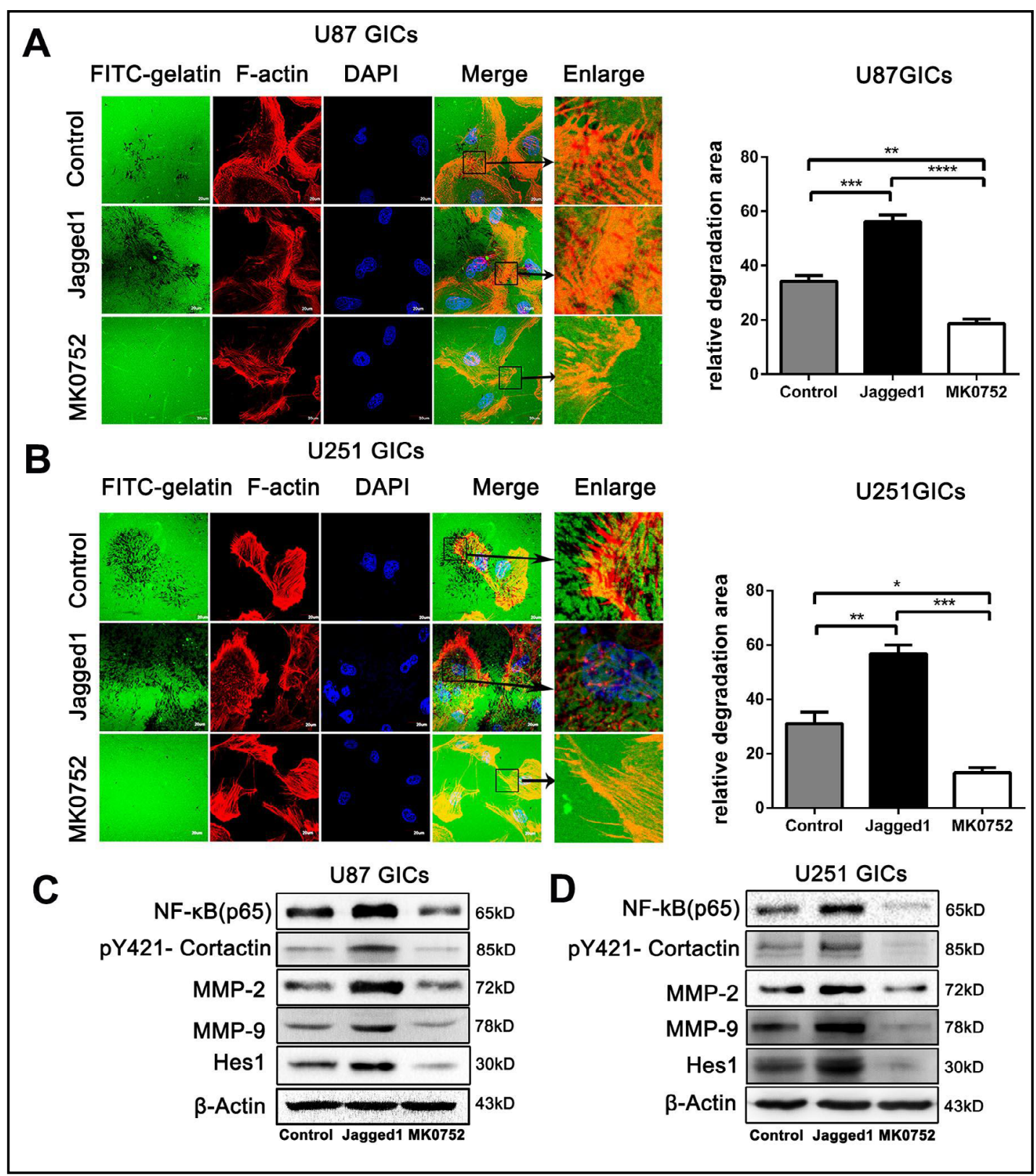

Fig. 3. Jagged1 regulated invadopodia-mediated matrix degradation. (A, B) Representative fluorescence images of F-actin (red), FITC-gelatin (green) and nuclei (blue) in U87 GICs and U251 GICs cells after Jagged1 ligand and MK0752 treatment. Areas of degradation appear as the well-defined black areas beneath the cells. Scale bar: $20 \mu \mathrm{m}$. (C, D) After Jagged1 ligand and MK0752 treatment, the Hes1, NF-кB(p65), pY421Cortactin, MMP-2, and MMP-9 expression levels were detected by Western blot. $\beta$-actin was used as a loading control. *: $\mathrm{P}<0.05,{ }^{* *}: \mathrm{P}<0.01,{ }^{* * *}: \mathrm{P}<0.001$.

Jagged1-induced invasion of GICs cells through activation of NF- $\kappa B(p 65)$ pathway

To further investigate the effects of Jagged1, shRNA was used to knockdownJagged1 in U87 GICs and U251 GICs cells. The efficacy of Jagged1 knockdown was confirmed by realtime PCR and western blot analysis (Fig. 4A and B). In Transwell invasion assays and matrix degradation assays, the collective representative data depicted that Jagged1-KD dramatically decreased the invasive ability of GICs cells (Fig. 4D and E). Next, we investigated the effect of NF- $\mathrm{KB}(\mathrm{p} 65)$ on the invasion in GICs cells. As shown in Fig. 4E, NF- $\mathrm{B}(\mathrm{p} 65)$ interference 
Fig. 4. Jagged 1 regulated GICs cells invasion by NF$\kappa \mathrm{B}(\mathrm{p} 65)$ signaling. (A, B) Western blot analysis was carried out to evaluate the expression of Jagged1 when GICs cells were transfected with negative control shRNA (shControl), Jagged1 shRNA (shJAG1). $\beta$-Actin was used as a loading control. (C) Western blot assays of Jagged1, Hes1, NF-кB(p65), pY421-Cortactin, MMP2 and MMP-9 expression levels in GICs cells after treatment with ShJAG1, ShJAG1+Jagged 1, SiNF$\mathrm{kB}(\mathrm{p} 65)$, and SiNF$\mathrm{k} \mathrm{B}(\mathrm{p} 65$ ) + J a g g e d 1 , $\beta$-actin was used as a loading control. (D) The representative images and histograms of in vitro Transwell invasion assays. (E) Representative fluorescence images of F-actin (red), FITCgelatin (green) and nuclei (blue) in U87 GICs and U251 GICs cells after treatment with Control, ShJAG1, SiNF-kB(p65). (F) Immunoprecipitated by antibodies targeting either NICD or NF- $\kappa B(p 65)$. Both the forward and reverse i m munoprecipitation actively indicated that NICD specifically bound to NF- $\kappa B(p 65) . *: \quad P<0.05$, **: $\mathrm{P}<0.01,{ }^{* * *}: \mathrm{P}<0.001$.
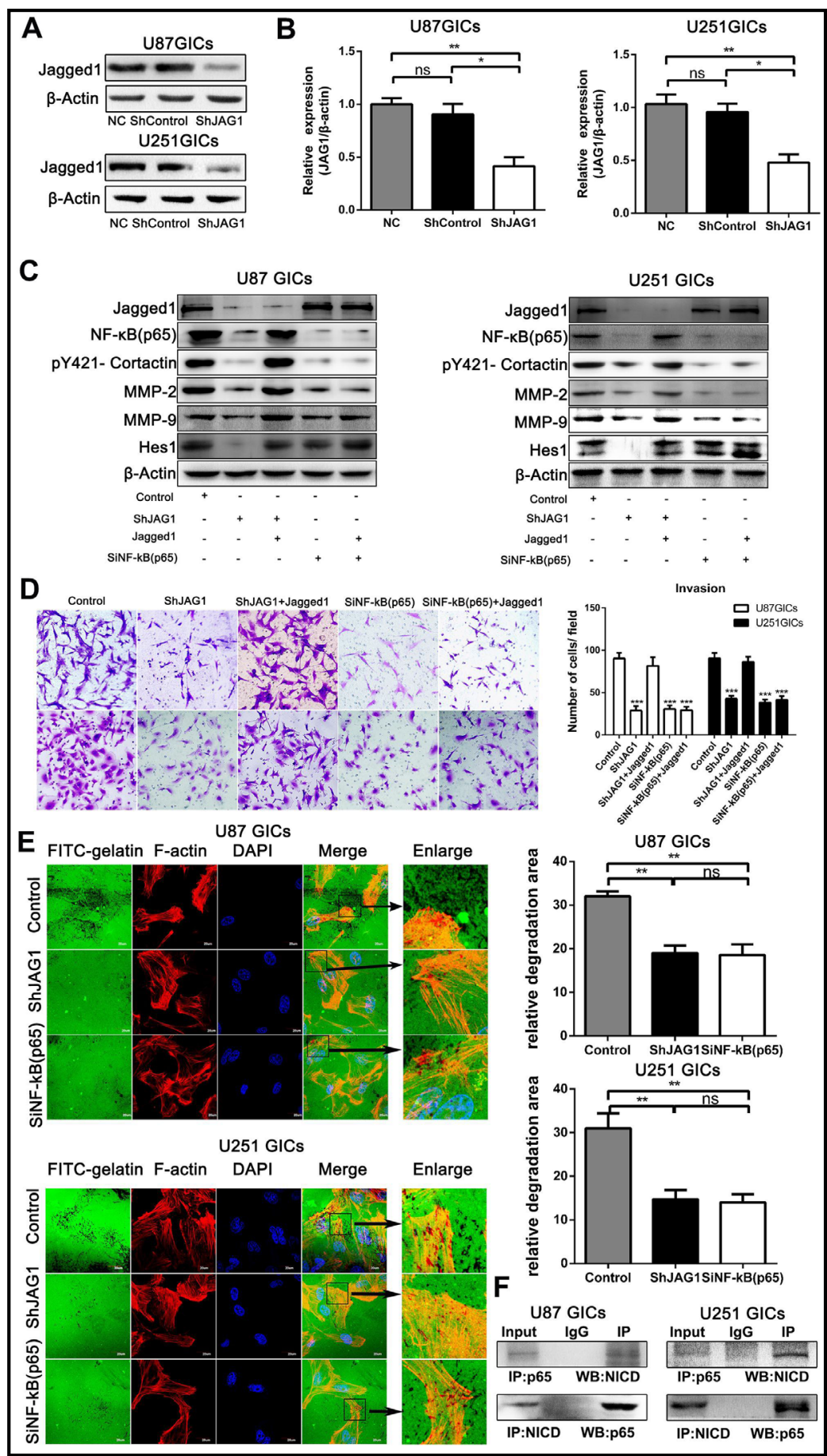

strongly inhibited cell invasion, compared with the Control group in GICs cell lines. Jagged1mediated Notch signaling activation notably enhanced the invasion abilities in both cell lines (Fig. 4F). However, in the siNF- $\kappa \mathrm{B}(\mathrm{p} 65)$-transfected cells (U87GICs-siNF- $\kappa \mathrm{B}(\mathrm{p} 65)$ cells and U251GICs-siNF- $\kappa B(p 65)$ cells), after incubation with Jagged1 protein, the inhibited invasion abilities could not be restored by Jagged1-induced Notch signaling activation (Fig. 4C). The expression levels of the protein markers associated with invasion were also not restored in siNF- $\mathrm{B}(\mathrm{p} 65)$ cells after Jagged1 ligand treatment (Fig. 4C). In addition, we performed coIP analysis and observed that NICD (cleaved Notch intracellular domain, the activated form 


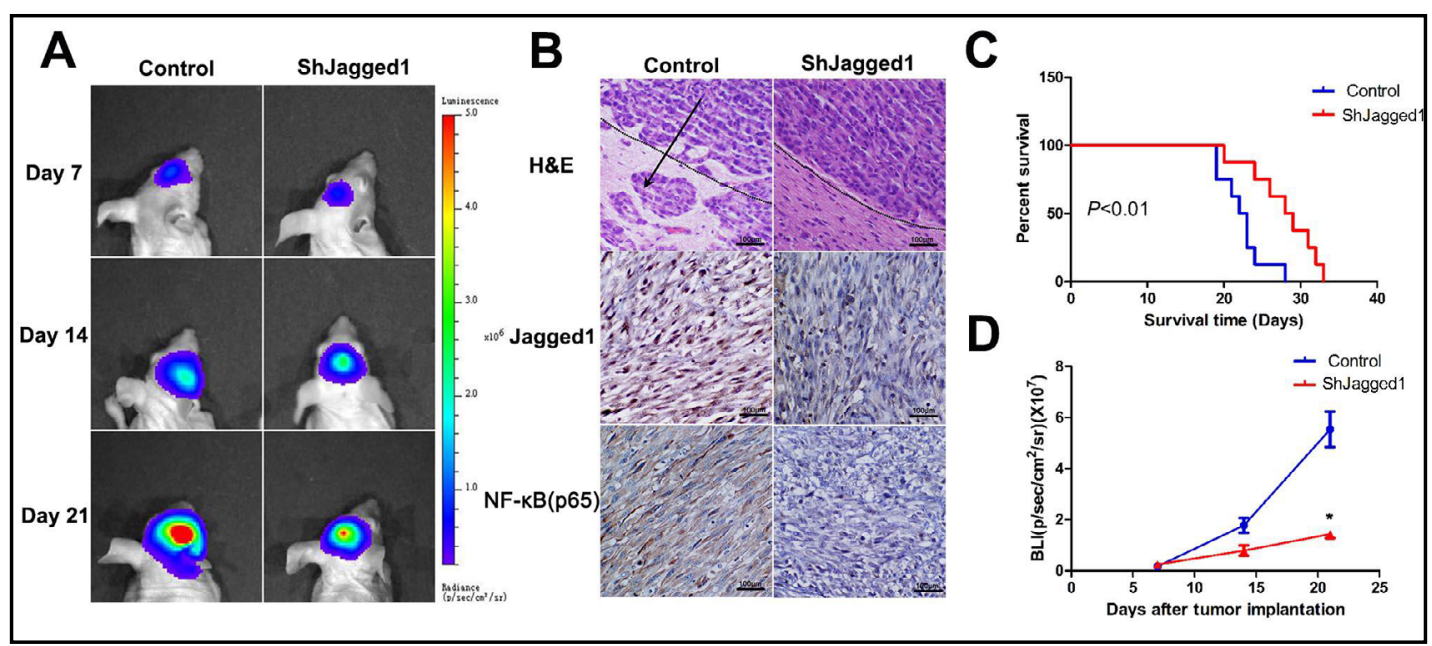

Fig. 5. Effect of downregulation of Jagged1 on the growth of xenograft tumors in nude mice. (A) Bioluminescent images from the ShControl, ShJagged 1 animals at 7, 14 and 21 days after tumor implantation. (B) Representative photomicrographs of H\&E staining and immunohistochemistry for Jagged1 and NF$\mathrm{kB}(\mathrm{p} 65)$ in sample tissues. (C) Mouse survival in the different groups was quantified with a Kaplan-Meier survival curve. (D) Bioluminescence (BLI) was performed to monitor tumor growth on days 7, 14, 21. *: $\mathrm{P}<0.05,{ }^{* *}: \mathrm{P}<0.01,{ }^{* * *}: \mathrm{P}<0.001$.

of Notch) can bind to NF- $\mathrm{kB}(\mathrm{p} 65)$ (Fig. 4F). Taken together, our data showed that Jagged1induced Notch signaling activation promotes the invasion mainly through activation of NF$\kappa \mathrm{B}(\mathrm{p} 65)$.

Silencing of Jagged1 suppressed NF- $\kappa B(p 65)$ signaling in vivo

We further tested whether knockdown of Jagged1 could suppress the tumorigenicity of GICs cells in vivo. Bioluminescence imaging showed tumor growth stasis in the Jagged1KD -treated group compared with the Control-treated tumors, and a statistically significant difference in tumor volume on the 21 day (Fig. $5 \mathrm{~A}$ and D). IHC analysis showed that Jagged1KD treatment specifically downregulated Jagged 1 and NF- $\mathrm{BB}(\mathrm{p} 65)$. H\&E staining of mouse brain tissues indicated that the boundary between the tumor and normal tissues in the Jagged1-KD groups was significantly clear compared with the control group (Fig. 5B). In addition, the Jagged1-KD groups mice exhibited significantly longer survival times (Fig. 5C). These data suggest that Jagged1 play a critical role in GICs invasion and NF- $\mathrm{B}(\mathrm{p} 65)$ signaling.

\section{Discussion}

Glioblastoma (GBM) is one of the most common and lethal primary malignant brain tumor in adults. The major reason that therapeutic treatments fail are due to the highly invasive nature of the tumor cells and the occurrence of increased angiogenesis [26]. GBM harbors a subpopulation of self-renewing, therapy-resistant cells, GICs. GICs are notably highly invasive and promote angiogenesis [27].

The abnormal activation of Notch signaling pathways augments the angiogenesis and invasiveness of GICs. The Notch ligands Dll4 and Jagged1 are upregulated in subsets of GBMs presenting an angiogenic phenotype. Zhu et al. showed ECs express Dll4 and Jagged1 that activate Notch receptors on the surface of GICs and promote GICs self-renewal [16]. Inhibition of Notch signaling with a $\gamma$-secretase inhibitor results in a decreased GIC selfrenewal, which depletes ECs in the vascular niche, and promotes GIC sensitivity to radiation therapy $[28,29]$. Dll4 is predominantly expressed in the endothelial cells (ECs) of tumor 


\section{Cellular Physiology Cell Physiol Biochem 2018;51:2925-2937

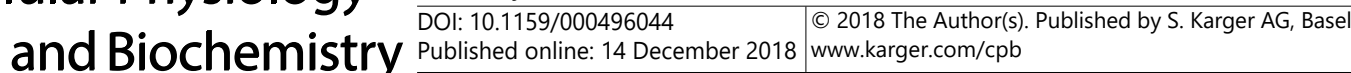 \\ Hai et al.: Jagged1 regulated GICs Invasion Through NF-kB(p65)}

blood vessels but also in a small proportion of tumour cells [30, 31]; whereas Jagged1, although also expressed in ECs, is more highly expressed in glioma cells [20]. Our data also confirm this discovery (Fig. 2B). This expression pattern suggests a pivotal role of Dll4 in the regulation of angiogenesis through the Notch receptors, whereas Jagged1 ligands may have another effect on gliomagenesis.

Previous studies reported that the Notch pathway plays an important role in normal stem cell biology. And this resulted in unacceptable levels of gastrointestinal toxicity when pan-Notch inhibitors ( $\gamma$-secretase inhibitors) was attempted using [32]. Unlike the Dll1/4ligands, Jagged1 was found to be dispensable for the homeostasis of normal intestinal stem cells, suggesting that targeting Jagged1 is less likely to have adverse side effects $[33,34]$. Therefore, it might be theoretically possible that targeting Jagged 1 is a more promising intervention for GBMs patients rather than targeting other Notch components. Several reports have described Jagged1 involvement in EMT and invasive potential $[35,36]$. Furthermore, Jagged 1 can increase tumor migratory and invasive behavior by inducing the urokinase-type plasminogen activator (uPA) [37]. Nevertheless, the effects of Jagged1 on GICs invasion were not been fully explored, and the underlying mechanism remains unclear.

In this study, we demonstrated that Jagged 1 expression was significantly increased with the grade elevation in Glioma France and Glioma Sun datasets. The glioma subgroups with lower level of Jagged1 were correlated with better prognoses, suggesting that Jagged1 the specific biomarkers for the prognostic-based glioma sub-classification. Furthermore, we found that Jagged1 mRNA levels were significantly elevated in classical and proneural subtypes of GBM. Anoop P et al. showed a "hybrid" states in primary glioblastoma highly for two subtypes; most commonly classical and proneural (progenitor states) or mesenchymal and neural (differentiated states) [38]. Then we used a GEO microarray data set (GDS3885) and observed that the Jagged1 were significantly upregulated in GICs. All findings presented revealed that Jagged1 may promote the development and progression of GICs. Subsequently, downregulation of Jagged1 expression led to a reduced GICs cell invasion. Our data also showed that NF- $\kappa \mathrm{B}(\mathrm{p} 65)$ expression was dramatically downregulated by Jagged1 knockdown. Similarly, a recent report has revealed that Notch signaling pathway inhibition results in decreased NF- $\kappa B$ in pancreatic cancer cells, suggesting a molecular link or cross-talk between Notch signaling and NF- $\kappa B(p 65)$ [39]. NF- $\kappa B$ signaling pathway is constitutively activated in glioma, and has been shown to contribute to the development and progression of tumors $[40,41]$. Several genes involved in invasion, such as ICAM-1, ZEB-1, uPAR, Cortactin, MMP2 and MMP9, have been identified as being regulated by NF- $\mathrm{KB}$ [4244]. Gene silencing of NF- $\kappa B$ (p65) by the application of small interfering RNA significantly reduced glioma cell invasion (Fig. 4E). We further found that the inhibited invasion abilities were also not restored in siNF- $\mathrm{BB}(\mathrm{p} 65)$ cells after Jagged1 ligand treatment. Finally, we found that NICD (cleaved Notch intracellular domain, activated form of Notch) can bind to $\mathrm{NF}-\kappa \mathrm{B}(\mathrm{p} 65)$. Overall, our results indicated that inhibition of NF- $\kappa \mathrm{B}$ (p65) signaling greatly suppressed Jagged1-induced cell invasion (Fig. 4C and D), suggesting that Jagged1 mediates the GICs invasions via NF- $\mathrm{B}(\mathrm{p} 65)$ signaling.

\section{Conclusion}

In summary, our study expands the understanding of the regulatory effects of Jagged 1 on GIC cells. The roles of the Jagged1-NF- $\mathrm{BB}(\mathrm{p} 65)$ interactions in GICs invasion need to be explored more deeply. The findings of this present study might help to guide the development of potential therapeutic targets for the prevention of GIC cells invasion. 


\section{Cellular Physiology Cell Physiol Biochem 2018;51:2925-2937 and Biochemistry Published online: 14 December $2018 \begin{aligned} & \text { (c) } 2018 \text { The Author(s). Published by S. Karger AG, Basel } \\ & \text { www.karger.com/cpb }\end{aligned}$}

Hai et al.: Jagged1 regulated GICs Invasion Through NF-kB(p65)

\section{Acknowledgements}

This work was supported by the National Natural Science Foundation of China (No.81472352 and No.81502171) and the Natural Science Foundation of Tianjin City (No.15JCZDJC36200)

\section{Disclosure Statement}

The authors declare that there is no conflict of interests in this work.

\section{References}

1 Stupp R, Hegi ME, Mason WP, van den Bent MJ, Taphoorn MJ, Janzer RC, Ludwin SK, Allgeier A, Fisher B, Belanger K, Hau P, Brandes AA, Gijtenbeek J, Marosi C, Vecht CJ, Mokhtari K, Wesseling P, Villa S, Eisenhauer $\mathrm{E}$, Gorlia $\mathrm{T}$ et al.: Effects of radiotherapy with concomitant and adjuvant temozolomide versus radiotherapy alone on survival in glioblastoma in a randomised phase III study: 5-year analysis of the EORTC-NCIC trial. Lancet Oncol 2009;10:459-466.

-2 Stupp R, Mason WP, van den Bent MJ, Weller M, Fisher B, Taphoorn MJ, Belanger K, Brandes AA, Marosi C, Bogdahn U, Curschmann J, Janzer RC, Ludwin SK, Gorlia T, Allgeier A, Lacombe D, Cairncross JG, Eisenhauer E, Mirimanoff RO: Radiotherapy plus concomitant and adjuvant temozolomide for glioblastoma. N Engl J Med 2005;352:987-996.

- Han S, Wang C, Qin X, Xia J, Wu A: LPS alters the immuno-phenotype of glioma and glioma stem-like cells and induces in vivo antitumor immunity via TLR4. J Exp Clin Cancer Res 2017;36:83.

-4 Ostrom Q Cohen ML, Ondracek A, Sloan A, Barnholtz-Sloan J: Gene markers in brain tumors: what the epileptologist should know. Epilepsia 2013;54 Suppl 9:25-29.

-5 Singh SK, Clarke ID, Terasaki M, Bonn VE, Hawkins C, Squire J, Dirks PB: Identification of a cancer stem cell in human brain tumors. Cancer Res 2003;63:5821-5828.

6 Bao S, Wu Q, McLendon RE, Hao Y, Shi Q Hjelmeland AB, Dewhirst MW, Bigner DD, Rich JN: Glioma stem cells promote radioresistance by preferential activation of the DNA damage response. Nature 2006;444:756-760.

7 Cheng L, Wu Q, Guryanova OA, Huang Z, Huang Q, Rich JN, Bao S: Elevated invasive potential of glioblastoma stem cells. Biochem Biophys Res Commun 2011;406:643-648.

8 Eramo A, Ricci-Vitiani L, Zeuner A, Pallini R, Lotti F, Sette G, Pilozzi E, Larocca LM, Peschle C, De Maria R: Chemotherapy resistance of glioblastoma stem cells. Cell Death Differ 2006;13:1238-1241.

-9 Qiang L, Wu T, Zhang HW, Lu N, Hu R, Wang YJ, Zhao L, Chen FH, Wang XT, You QD, Guo QL: HIF-1 $\alpha$ is critical for hypoxia-mediated maintenance of glioblastoma stem cells by activating Notch signaling pathway. Cell Death Differ 2012;19:284-294.

-10 Hu YY, Zheng MH, Cheng G, Li L, Liang L, Gao F, Wei YN, Fu LA, Han H: Notch signaling contributes to the maintenance of both normal neural stem cells and patient-derived glioma stem cells. BMC Cancer 2011;11:82.

-11 Stockhausen MT, Kristoffersen K, Poulsen HS: The functional role of Notch signaling in human gliomas. Neuro Oncol 2010;12:199-211.

12 Bolós V, Grego-Bessa J, de la Pompa JL: Notch signaling in development and cancer. Endocr Rev 2007;28:339-363.

13 Benedito R, Roca C, Sörensen I, Adams S, Gossler A, Fruttiger M, Adams RH: The notch ligands Dll4 and Jagged1 have opposing effects on angiogenesis. Cell 2009;137:1124-1135.

14 Jubb AM, Browning L, Campo L, Turley H, Steers G, Thurston G, Harris AL, Ansorge O: Expression of vascular Notch ligands Delta-like 4 and Jagged-1 in glioblastoma. Histopathology 2012;60:740-747.

15 Cohen B, Shimizu M, Izrailit J, Ng NF, Buchman Y, Pan JG, Dering J, Reedijk M: Cyclin D1 is a direct target of JAG1-mediated Notch signaling in breast cancer. Breast Cancer Res Treat 2010;123:113-124. 


\section{Cellular Physiology Cell Physiol Biochem 2018;51:2925-2937 and Biochemistry \begin{tabular}{l|l} 
DOI: 10.1159/000496044 & $\begin{array}{l}\text { (c) } 2018 \text { The Author(s). Published by S. Karger AG, Basel } \\
\text { www.karger.com/cpb }\end{array}$
\end{tabular}}

Hai et al.: Jagged1 regulated GICs Invasion Through NF-kB(p65)

-16 Zhu TS, Costello MA, Talsma CE, Flack CG, Crowley JG, Hamm LL, He X, Hervey-Jumper SL, Heth JA, Muraszko KM, DiMeco F, Vescovi AL, Fan X: Endothelial cells create a stem cell niche in glioblastoma by providing NOTCH ligands that nurture self-renewal of cancer stem-like cells. Cancer Res 2011;71:60616072.

17 Lu J, Ye X, Fan F, Xia L, Bhattacharya R, Bellister S, Tozzi F, Sceusi E, Zhou Y, Tachibana I, Maru DM, Hawke DH, Rak J, Mani SA, Zweidler-McKay P, Ellis LM: Endothelial cells promote the colorectal cancer stem cell phenotype through a soluble form of Jagged-1. Cancer Cell 2013;23:171-185.

$>18$ Leong KG, Niessen K, Kulic I, Raouf A, Eaves C, Pollet I, Karsan A: Jagged1-mediated Notch activation induces epithelial-to-mesenchymal transition through Slug-induced repression of E-cadherin. J Exp Med 2007;204:2935-2948.

19 Wang Z, Li Y, Kong D, Banerjee S, Ahmad A, Azmi AS, Ali S, Abbruzzese JL, Gallick GE, Sarkar FH: Acquisition of epithelial-mesenchymal transition phenotype of gemcitabine-resistant pancreatic cancer cells is linked with activation of the notch signaling pathway. Cancer Res 2009;69:2400-2407.

20 Oon CE, Bridges E, Sheldon H, RCA S, Jubb A, Turley H, Leek R, Buffa F, Harris AL, Li JL: Role of Delta-like 4 in Jagged1-induced tumour angiogenesis and tumour growth. Oncotarget 2017;8:40115-40131.

-21 Purow BW, Haque RM, Noel MW, Su Q Burdick MJ, Lee J, Sundaresan T, Pastorino S, Park JK, Mikolaenko I, Maric D, Eberhart CG, Fine HA: Expression of Notch-1 and its ligands, Delta-like-1 and Jagged-1, is critical for glioma cell survival and proliferation. Cancer Res 2005;65:2353-2363.

22 Zhang C, Hai L, Zhu M, Yu S, Li T, Lin Y, Liu B, Zhou X, Chen L, Zhao P, Zhou H, Huang Y, Zhang K, Ren B, Yang X: Actin cytoskeleton regulator Arp2/3 complex is required for DLL1 activating Notch1 signaling to maintain the stem cell phenotype of glioma initiating cells. Oncotarget 2017;8:33353-33364.

23 Zhu M, Chen L, Zhao P, Zhou H, Zhang C, Yu S, Lin Y, Yang X: Store-operated Ca(2+) entry regulates glioma cell migration and invasion via modulation of Pyk2 phosphorylation. J Exp Clin Cancer Res 2014;33:98.

24 Wang FY, Kang CS, Wang-Gou SY, Huang CH, Feng CY, Li XJ: EGFL7 is an intercellular EGFR signal messenger that plays an oncogenic role in glioma. Cancer Lett 2017;384:9-18.

-25 Artym VV, Yamada KM, Mueller SC: ECM degradation assays for analyzing local cell invasion. Methods Mol Biol 2009;522:211-219.

26 Keller S, MHH S: EGFR and EGFRvIII Promote Angiogenesis and Cell Invasion in Glioblastoma: Combination Therapies for an Effective Treatment. Int J Mol Sci 2017;18.

27 Calabrese C, Poppleton H, Kocak M, Hogg TL, Fuller C, Hamner B, Oh EY, Gaber MW, Finklestein D, Allen M, Frank A, Bayazitov IT, Zakharenko SS, Gajjar A, Davidoff A, Gilbertson RJ: A perivascular niche for brain tumor stem cells. Cancer Cell 2007;11:69-82.

28 Wang J, Wakeman TP, Lathia JD, Hjelmeland AB, Wang XF, White RR, Rich JN, Sullenger BA: Notch promotes radioresistance of glioma stem cells. Stem Cells 2010;28:17-28.

29 Hovinga KE, Shimizu F, Wang R, Panagiotakos G, Van Der Heijden M, Moayedpardazi H, Correia AS, Soulet D, Major T, Menon J, Tabar V: Inhibition of notch signaling in glioblastoma targets cancer stem cells via an endothelial cell intermediate. Stem Cells 2010;28:1019-1029.

-30 Li JL, Sainson RC, Oon CE, Turley H, Leek R, Sheldon H, Bridges E, Shi W, Snell C, Bowden ET, Wu H, Chowdhury PS, Russell AJ, Montgomery CP, Poulsom R, Harris AL: DLL4-Notch signaling mediates tumor resistance to anti-VEGF therapy in vivo. Cancer Res 2011;71:6073-6083.

-31 Li JL, Sainson RC, Shi W, Leek R, Harrington LS, Preusser M, Biswas S, Turley H, Heikamp E, Hainfellner JA, Harris AL: Delta-like 4 Notch ligand regulates tumor angiogenesis, improves tumor vascular function, and promotes tumor growth in vivo. Cancer Res 2007;67:11244-11253.

-32 Imbimbo BP: Therapeutic potential of gamma-secretase inhibitors and modulators. Curr Top Med Chem 2008;8:54-61.

-33 Pellegrinet L, Rodilla V, Liu Z, Chen S, Koch U, Espinosa L, Kaestner KH, Kopan R, Lewis J, Radtke F: Dll1and dll4-mediated notch signaling are required for homeostasis of intestinal stem cells. Gastroenterology 2011;140:1230-1240.e1-7.

34 Li D, Masiero M, Banham AH, Harris AL: The notch ligand JAGGED1 as a target for anti-tumor therapy. Front Oncol 2014;4:254.

35 Shao S, Zhao X, Zhang X, Luo M, Zuo X, Huang S, Wang Y, Gu S, Zhao X: Notch1 signaling regulates the epithelial-mesenchymal transition and invasion of breast cancer in a Slug-dependent manner. Mol Cancer $2015 ; 14: 28$. 


\section{Cellular Physiology Cell Physiol Biochem 2018;51:2925-2937

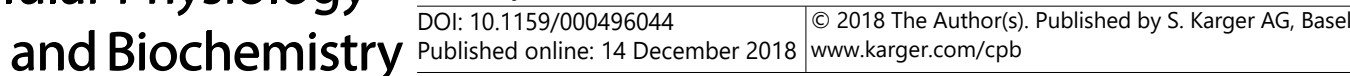

-36 Zavadil J, Cermak L, Soto-Nieves N, Böttinger EP: Integration of TGF-beta/Smad and Jagged1/Notch signalling in epithelial-to-mesenchymal transition. EMBO J 2004;23:1155-1165.

-37 Shimizu M, Cohen B, Goldvasser P, Berman H, Virtanen C, Reedijk M: Plasminogen activator uPA is a direct transcriptional target of the JAG1-Notch receptor signaling pathway in breast cancer. Cancer Res 2011;71:277-286.

-38 Patel AP, Tirosh I, Trombetta JJ, Shalek AK, Gillespie SM, Wakimoto H, Cahill DP, Nahed BV, Curry WT, Martuza RL, Louis DN, Rozenblatt-Rosen O, Suvà ML, Regev A, Bernstein BE: Single-cell RNA-seq highlights intratumoral heterogeneity in primary glioblastoma. Science 2014;344:1396-1401.

-39 Zhu H, Bhaijee F, Ishaq N, Pepper DJ, Backus K, Brown AS, Zhou X, Miele L: Correlation of Notch1, pAKT and nuclear NF- $\kappa$ B expression in triple negative breast cancer. Am J Cancer Res 2013;3:230-239.

40 Li L, Gondi CS, Dinh DH, Olivero WC, Gujrati M, Rao JS: Transfection with anti-p65 intrabody suppresses invasion and angiogenesis in glioma cells by blocking nuclear factor-kappaB transcriptional activity. Clin Cancer Res 2007;13:2178-2190.

41 Lee J, Hoxha E, Song HR: A novel NFIA-NFкB feed-forward loop contributes to glioblastoma cell survival. Neuro Oncol 2017;19:524-534.

$\checkmark 42$ Chang HJ, Kim MH, Baek MK, Park JS, Chung IJ, Shin BA, Ahn BW, Jung YD: Triptolide inhibits tumor promoter-induced uPAR expression via blocking NF-kappaB signaling in human gastric AGS cells. Anticancer Res 2007;27:3411-3417.

43 Yang CJ, Liu YP, Dai HY, Shiue YL, Tsai CJ, Huang MS, Yeh YT: Nuclear HDAC6 inhibits invasion by suppressing NF- $\mathrm{KB} / \mathrm{MMP} 2$ and is inversely correlated with metastasis of non-small cell lung cancer. Oncotarget 2015;6:30263-30276.

44 Hill A, McFarlane S, Mulligan K, Gillespie H, Draffin JE, Trimble A, Ouhtit A, Johnston PG, Harkin DP, McCormick D, Waugh DJ: Cortactin underpins CD44-promoted invasion and adhesion of breast cancer cells to bone marrow endothelial cells. Oncogene 2006;25:6079-6091. 